\title{
ARTISTIC INTERVENTIONS AND PERFORMANCES INSIDE DIGITAL ENVIRONMENTS
}

\author{
F. Javier Longobardo Polanco
}

\author{
AUE (American University in the Emirates, Dubai
}

\begin{abstract}
In this paper, I underline the similarities between historical art strategies, represented by Land Art, Povera and Performance Art, and those applied today by artists working with video-game technology. The former were art movements interested in the immediate experience of our surrounding reality. They overflowed the boundaries of the conventions of art by taking over the physical presence of space, objects and our bodies as their medium for work: they proposed aesthetic experiences that questioned the "cultural layer" we interpose between our senses and nature. A generation of artists working with videogames also claim some immediate experience: one from the intangible domains of the digital. They embrace another "cultural layer", one that necessarily interposes between us and the intangible nature of the digital. That layer is the User Interface, a technology that allows us to operate the new media by means of metaphors of our familiar nature: space, time, objects, beings and physical phenomena. The interface of a video game represents a "habitable" blend of our physical experience with the fantastic possibilities of the digital: we can feel it and intervene in it, embodied in avatars. The artistic proposals and interventions inside video games warn and inform us about the hybrid context of the digital.
\end{abstract}

Keywords: video games; performance; digital; environment

\section{Introduction}

We have had thousands of years to experience our physical nature, to develop our culture based on the relations we establish with our natural surroundings. We have accumulated a massive background of information and we've tested our achievements in many contexts, in relation to our space and our culture. And we have developed technologies that have influenced the vision of our reality: "we shape our tools and thereafter our tools shape us" (McLuhan, 1995).

Since not much more than two decades ago, we have massively signed up to digital technology: one we can interact with by using the tools of the New Media; forms of media that are native to computers. We are increasingly used to living in a digital context, but there is still an ongoing struggle in establishing the rules for that abstract and invisible terrain: we call it the "cyberspace", but we're still reluctant to accept it as a real place:

"Just because something is not material does not mean it is unreal, as the oft-cited distinction between "cyberspace" and "real space" implies. Despite its lack of physicality, cyberspace is a real place. I am there-whatever this statement may ultimately turn out to mean." (Wertheim M., 1999, p 229)

Still, we are used to enjoying the conveniences of the new media. We do not need to explain that, nor do we need to explain the general feeling that part of our life belongs to a world we cannot control: 
"(...)algorithms are already analyzing social media habits, determining creditworthiness, deciding which job candidates get called in for an interview and judging whether criminal defendants should be released on bail.(...) These systems leave no room for humanity, yet they define our daily lives." (Chelsea Manning, 2017, 13th September)

To deal with our cultural arte facts and understand the concepts, we need visualizations, metaphors. Heaven and Hell, for example, are commonly represented in literature and art, as pleasant gardens or claustrophobic caverns of fire to effectively communicate their potential effects on the human spirit or soul. Video games are spatial visualizations too: spaces with specific rules that have a cause-and-effect result from human activity therein. They function as visual metaphors for operating in the mathematical nature of the digital. Their natural looking environments can be altered or disrupted the same way land artists do to physical space.

\section{The Context of the Digital: the Two Layers}

"(...) new media in general can be thought of as consisting from two distinct layers: the "cultural layer" and the "computer layer." The examples of categories on the cultural layer are encyclopedia and a short story; story and plot; composition and point of view; mimesis and catharsis, comedy and tragedy. The examples of categories on the computer layer are process and packet (as in data packets transmitted through the network); sorting and matching; function and variable; a computer language and a data structure." (Manovich, 2002, 63)

In his book The Language of New Media, Manovich suggests dividing/thinking about New Media into two different layers, the 'culture layer' and the 'computer layer'. In this paper, I will refer to his definition of the new media and the metaphor of the two layers.

Given the fact that the Digital is a cultural artifact, a product of human thought, we might say that it is an independent world, independent from our physical nature.

Even though we see a picture or a text in a similar way as we see it on a book or a canvas, its nature is totally different: once digitized any cultural object has been transformed in numeric values, and it functions under the logic of mathematics; it is the condition and the advantage of entering the realm of the digital, the computer layer.

Now, how would we operate with our text or images once they have been digitized (dematerialized)? We do it by means of its visual representation on the screen: the User Interface (UI). That is our intermediary for dialoguing with the computer (or other devices such as mobiles). As the role of the UI is to establish a comfortable relation between us and the computer, it generally depicts elements familiar to us: the desktop, the windows, the deejay mixing desk, space...The UI of a video game is displayed in many ways; there is always the space (environment), the context in which we play and perform. The depicted space itself is an "intruder" in the mathematical realm of the digital. Thus, what we get is a "cross-bred" reality, a projection of our understanding of the world, in a domain that operates under mathematical rules.

What we want to point out is the friction and the mutual influence between the two layers: we are developing digital technology in a way that matches our interests. We created the internet to facilitate our communication; therefore, the computer layer has been developed under our cultural premises since its inception. We also constrain the computer layer's visibility by limiting the possibilities of the UI: Its interactive options are based on human interests, not only for better performance, but also to keep our social and economic system as it is in the physical world. For example, we have to pay for information, for eBooks and images in a way that clearly reflects a resistance to adapting to a technology that offers the ubiquity of information: we have imported shortage into the digital. 
To be operational and provide a realistic embodied experience, one that recalls our physical experience, we import artificial constraints: the video game's environments provide simulations of the phenomena and laws of physics: we walk and run, we overcome obstacles, we fight and crash, we need energy and eventually, we die. All these situations have nothing to do with the digital technology; they are just representations of the physical world.

Still, the computer layer reveals itself every day. Ona visual level we can see it as glitches or errors in the metaphorical surface of the UI: we find the expressiveness of the medium in the fissures of the cultural layer, just as we see the paint drops on a painting or the cracks in a clay sculpture.

\section{Video games: Inhabitable Metaphors}

Without considering whether video games are art or not, the fact is that they have been a common option for entertainment for decades already. And just like every technology, artists have started experimenting with them in many ways. The uniqueness of videogames resides in their capacity to be used as a moldable tool and also as an inhabitable environment. Such experience can be attained inside the User Interface (UI) of the video games, by means of the avatar: our digital double in the digital environments; it allows us to achieve an embodied experience, not physical, but real in our minds.

"Unlike the spaces of film, paintings, and photography, videogame spaces are spaces that are both observed and engaged directly; they are thus experiential spaces.” (Taylor, 2002, p.19)

Because digital technology is based upon mathematical logic, the interface of the video game is developed with our standard, historical tools for spatial representation on a flat surface (the screen): mainly, the orthographic projection system, the three-point perspective and the cavalier perspective. Such visual recourses demonstrate how the metaphors of space, nature, beings, and objects are deployed in, and by means of, an abstract digital nature that has nothing to do with them.

Thus, video games have the qualities required to figure out the invisible and the abstract human constructs. It is not a coincidence that scientists created video games as early UIs (User Interface) to interact with their primitive computers: Space War! (1962), developed by Steve Russell at MIT, already supported some basic metaphors of our physical environment such as space, gravity and inertia. Since then and throughout their historical evolution, video games have been providing varied environments and settings where one can interact with inanimate or animated beings. Embodied in our avatars, we can walk, crash or interact with the bot (robots, computer-driven characters) or with other humans (as avatars too).

Another interesting fact about video games is that they are themselves metaphors for the digital context: any digital content is a limited parallel reality, every sound and every image, once transcoded into digital technology, represents a compressed and limited version of our physical reality. And a video game is just a game: an agreed reality based on a limited set of rules.

A generation of artists has been working with video games for more than two decades already, very often addressing social and political concerns: video games are a new way of depicting our vision of the world and the narratives they convey are not neutral. A game represents a simplified emulation of our living tasks and situations in real life. Deliberate or not, games have an educational influence: they are a product of the New Media, and as any technology, they contribute to shaping us.

\section{Implementing Art Strategies Inside Video Games. The distancing effect}

The first intervention that artists perform inside video games lies in breaking the rules. This can be done in diverse ways: ignoring the goals, intervening in the programming codes or by creating video games that lack 
goals, and self-play "games". Rejecting the video game's objectives is a rejection of their narrative. We are talking about the same phenomena that took place in the last century, when artists decided to drift apart from the vision of art as vehicle of emotions or ideas: the affinity with represented themes became an obstacle for aesthetic experience. "Art cannot be subject to unconscious phenomenon for it ought to be all clarity, the high noon of cerebration" (Gasset, 1925, p 64). Similar claims are those made by the playwright Bertold Brecht, who coined the term "distancing effect" to address his claims for preventing the emotional involvement of the audience:

"(the)distancing effect (...) It involves the use of techniques designed to distance the audience from emotional involvement in the play through jolting reminders of the artificiality of the theatrical performance" (The Editors of Encyclopedia Britannica, 2000).

The stance against the rules, the system, the tradition, and any form of established culture or ideas, is a common paradigm in the development and evolution of culture. During the 20th century, the visual arts evolved driven/ignited by the necessity of revealing the hidden: the reality that exists beneath representation. Most of the resulting art movements, such as Abstract Art, Minimal Art, Conceptual Art, Performance Art, Fluxus, Earth Art or Povera Art, share the claim to a pristine experience: an experience that starts with attempts to reject our cultural layers as they see them as obstacles to perception. The expulsion of the pictorial landscape from the avant-garde of artistic thought did not diminish interest in the nature of art, but in the implementation of art as vehicle for content. Twentieth-century art about nature-Land art-consists of interventions in real nature. Povera art reclaims the expressive and essential presence of quotidian materials and objects, that is, one conception of nature more appropriate for post-industrial society; a different culture. During the twentieth century, the artist stopped painting nature and went out to find it. Performance art faces physical reality by playing with body presence and its relation with space and the others (performers and/or audience).

The outcomes of such art movements are varied but, still, they share a frontal opposition to any form of cultural layer - the layers that come between our immediate experience and the physical presence of what we see. The immediate and obvious layer is the metaphor: representation by means of familiar elements. The User Interfaceis the inevitable metaphor we use to communicate with the computer. Still, it is a dangerous cultural arte fact, because it can affect our understanding of what lies behind: "The metaphor conceals an object, masking it with another, and it would not make sense if we did not see underneath an instinct that induces man to avoid realities" (Ortega y Gasset, 1925, p 70.)

Therefore, by breaking the rules, artists manifest their intention of achieving a new experience in the video game environment - just like the claims of twentieth-century artists to reveal the actual medium, the flatness of the canvas and the physical presence of the colors. It is a claim against art as a narrative format.

\section{Evasive Actions for Contemplation}

"In the same way that the impressionists focused on nature, computer landscape became for my generation the most important subject matter." (Miltos Manetas 2010)

Some artists using video games as a medium, and performing inside them, are depicting their environments as landscapes on canvas. It is not by avoiding the representation of the environment in a more or less figurative way, but by rejecting the rules of the game, that they adhere to the historical art strategy of dismissing the narrative. The narrative seeks the emotional engagement of viewers; it distracts us and, eventually, hides the physical evidence.

Joan Pamboukes, Kristoffer Zetterstrand, Stefano Opera, Games Edu Uu, and Petri Hytönen paint, print or record landscapes taken from the environments of GTA (Grand Theft Auto); they experience the beauty of the naturalistic metaphors. The final output of their work depicts landscapes after landscapes — meta-landscapes, 
actually. Such artworks seem to convey the traditional nostalgia of nature, typical of landscapes. Consequently, they reveal a claim for the inhabited metaphor, the space of the video game as an experienced reality. Depicting meta-landscapes turns out to be an artistic action that reaffirms an embodied experience. In On the Road (2015, Games Edu Uu) takes a long motorcycle ride inside Grand Theft Auto - that is, a lived experience as one of the avatars in the game. The video from Edu Uu's journey belongs to the genre of machinima, movies recorded using the space and the characters of video games. Cyberspace has become a familiar scenario. Another representative project, GTA-SAGA, a series of watercolors by Petri Hytönen, documents one year of immersion in the virtual world of GTA: memories of experiences.

The above examples of artworks produced from experiences in video-game environments address the processes and outcomes of Land Art works: experiencing the environment and, as a second step, documenting it for the audience. This is how, manifestly or not, art is encouraging us to assume the digital environment as a reality.

Wesley W. Wilson's Air Combat (2011) is an interactive self-playing modded (manipulated) console video game. It is a clear example of the approaches to contemplative experiences we can achieve once rejecting the original goal of the game: to outlast the enemies and avoid crashing. Thus, we can enjoy the flight and the landscape provided by the game:

"You always pay attention to surviving and completing objectives, but actually the visuals and flying are very beautiful by them self[sic]. I used this game because I wanted to make a piece about endless flying (...)The result is just an airplane moving slowly over oceans and continents, with clouds passing by." (Wesley W. Wilson, 2011)

GTA-SAGA (2006-07). This series of watercolors, by Petri Hytönen (1963) documents his immersive experience wandering inside Grand Theft Auto, the video game, throughout one year. The fascinating cross-bred worlds of the digital, where realistic- looking environments can cohabit with the fantasy of the immaterial, is a seductive and inspiring experience only video games provide. Apart from the aesthetics of his watercolors, the fact of painting them, based on his daily journeys embodied as an avatar inside the game, reaffirms the authenticity of the space and events experienced. Those watercolors are, in fact, memories.

\section{The secret life of bots and avatars}

Not only the environments, but also the avatars and bots that populate them are deserving of the attention of a generation of artists: Mario Sleeping (Miltos Manetas, 1997) is a recording of the famous character in a rest attitude, one that the character adopts when the player stops playing for a while. This simple evasive or abstaining attitude in the game switches our resident states: we abandon our embodiment as Mario's avatar, and we become witnesses of his life. Manetas states, "It was about how to start listening to the newest side of the world! It was about permitting these newcomers, our intelligent machines, to come forward and reveal their stories." (Manetas, 1997)

Another artwork by Manetas, King Kong After Peter Jackson (2006), shows the performance of the avatars while not being played by the gamer: during their stay on the hostile, stormy island, they look as if they are waiting for instructions in an eerily human-like, expectant attitude.

Those artworks document Manetas's aesthetic experience: his consciousness-raising of Mario and King Kong's characters as living creatures, in the context of the game's reality.

Instead of playing, Manetas invites us to contemplation: we become emotionally distant observers, aliens inside the narrative of the game. By refusing to get involved in the game, we are free to experience the reality that is displayed in front of us. As I noted, the strategy of distancing ourselves from the plot and from sentimental 
participation is similar to that of thinkers and philosophers such as Bertold Brecht and Ortega y Gasset, who claimed it to be an essential element in the new art.

Somewhat humorously, Yann Bauquesne also reveals the oddness of a video game without game, the autonomous life of bots, and, ultimately, the fantastic cohabitation of realistic setups and infringements of the laws of nature. All those are elements that define digital reality. Bauquesne makes in-game modifications and performances inside such environments. He performs in scenarios without enemies, or produces surrealistic scenes with objects and soldiers that behave strangely. Thus, he breaks the death and rebirth logic of the firstperson shooter characters; in return, we receive a simple and neutral space. Strangeness (alienation) is the first step to attaining new experiences.

\section{Recreations and updates}

The phenomenon of the transcodification of our cultural arte facts into video-game environments challenges our thoughts on culture itself and, on the other hand, reveals the nature of the New Media. For example, a book or a painting can be easily recreated (digitized); the outcome would express specific qualities of the medium - in this case, the non-linearity of the digital content.

The technology of photography raised the discussion on the role of paintings as a tool for documenting our reality, denoting at the same time the physical evidence of the canvas and the pigments.

Regarded essentially as a child of technical rather than aesthetic traditions, the medium [of photography] is inevitably considered an outsider, which proceeded to disrupt the course of painting. The extreme corollary of this conception is the notion that photography adopted (or usurped) the representational function of painting, allowing (or forcing) painting to become abstract. This argument (...) seems to have been launched around 1900 by painters, who used it to justify their rejection of nineteenth-century naturalism. The argument has its roots in the conviction born in 1839 - that photography is the epitome of realism.(Galassi, 1981, p 12)

Thus, every time a new technology is developed, all of our cultural achievements and outcomes are being tested. Nevertheless, our existential questions remain the same throughout human history. Some artists working with video games are not so interested in exploring the nature of the video game itself; rather, they use them as an "updated" medium to express eternal concerns about human identity and existence.

In Waiting For (2011), the artist Olle Essvik depicts the absurdity, the repetitions and the limitations of our lives by means of the non-linear narrative of video games. As Essvik notes, Waiting For is an updated version of the famous play, Waiting for Godot, by Samuel Beckett. In the context of the medium of the video game, the repetition of the actions and events is generated by logarithmic calculations: they happen in real time, with unpredictable variations. Conversely, in a script or a book, they are fixed.

\section{Waiting For is described by Essvik as:}

"A theatrical play with a number of set instructions constantly repeated, but each time in a different order. The piece consists of a programmed and interactive animation sequence shown online and resembling a computer game, but where the concept has been expanded and the actual game element has been left out." Essvik (as cited in Jasson, 2015, p 67).

Quake/Friends (2002-03) is an online performance conceived by Joseph DeLappe, which uses the ultra-violent video game Quake as a theater for playing the famous TV show Friends. During the performance, the participants play the video game and at the same time, each one is assigned a character from Friends. In turns, they type and recite the text from the original script. Being killed does not stop them from playing the game or from continuing writing the script. Both worlds are superficial and unreal; Delappe criticizes that simplicity: 
"Mr. DeLappe said he was motivated to combine the brutal 'Quake' and the genteel 'Friends' because both are pop-culture creations that 'present a fantasy, a simplistic view' of the world. $\mathrm{He}$ said the 'Friends characters' happy life in New York is 'this perfect existence, and it's totally fake.' To him the 'Quake' violence is equally phony. 'You're killed but you're instantly O.K.,' he said. 'There's no real consequences to it.." DeLappe (as cited in Mirapaul, 2003)

Dead-in-Iraq (2006-2011). This is another performance inside a video game by DeLappe consisting of writing the names, and dates of death, of real American soldiers in the Iraqi war. This time, his theatre of play is the online video game "America's Army", a US Army recruiting game. By introducing information about real losses of lives he disturbs the entertainment of the players and drops a cautionary message on the board.

In the end, DeLappe's discourse represents a critique against the way humankind develops narratives that, ultimately, distract us from reality, giving us a false and superficial depiction of our existence: entertainment is a powerful tool for lulling the masses. Thus, he shares the mentioned claim for an experience free of goals and narrative arte facts.

\section{Metaphor and Nature Coexistence in Digital Environments: Short circuits.}

The increasing level of the visual realism of videogames is a consequence of the technical progress achieved over the last few decades. Even though they do not surpass the emotional engagement of the primitive games from the early eighties, there is a remarkable difference: the technological medium is not as obvious as it used to be. The aesthetics of pixels, the reduced color palette or the 8 bits sound were symptoms of the limitations of the first generations of domestic computers: clearly, the medium was expressing its nature. Today's video games tend to emulate the realism of movies. For instance, there are non-playable video sequences in between the game levels. They are displayed to create expectation, to meet new characters or the upcoming goals and to give a player a break. These sequences, under the name of "cut scenes," look rather like a movie scene than a video game. They are pre-created short movies, and as they are not processed "live", they can display "better" quality than the game itself. Still, the boundaries between the cut scenes and the actual game get thinner every year.

As visual realism represents the first target to undermine for those opposed to the emotional involvement of the audience, and, in particular, for the predominant art movements of the past century, it is also the subject for today's artists working with video games. The realism conceals the "true" digital nature of this environment, and so must be rejected. Paradoxically, however, we cannot reject the metaphor if we want to interact with the computer. Still, some artists find ways to remind us that our "life on the screen" is a hybrid reality.

JODI (Joan Heemskerk and Dirk Paesmans) have been developing strategies to reveal the hidden computer layer. One of their artworks, SOD, is a mod (modification) of the video game Wolfenstein, a pioneer in the FPS (first-person shooter)genre. They hacked the game in such a way that it displays simple geometric elements, such as black lines and squares over a plain white background, in the place of the creatures that populate the original game:

“(videogames)...are very explicit graphically and what we wanted to do was, in general, to erase the story and the figurative site of these games" JODI (as cited in Hunger, 1999, p 155)

Not in vain, they started creating Net Art works. Net Art is an artistic movement concerned about the transparency of the computer layer: "net art acts on computer networks, and is acted on by them" (Connor, 2015).

In Max Payne: CHEATS ONLY, we can see the characters constantly repeating absurd gestures, trying to go through walls, altered behaviors. Cheating games is a conventional way of making things easier for the player, for example, being invulnerable. JODI's cheats, however, refer to the game manipulations they have done to 
reveal the artificiality of the realistic environment and characters: we can see human figures passing through walls and getting stuck in the middle; characters revealing their immateriality as hollow polyhedrons, and other (physically) "impossible" events. Gravity, obstacles, the space itself, these are all physical realities imported into video games. Here, JODI's discourse deals with the friction of realities inside the video-game environments: the intangible nature of the digital domain and the realistic depictions for the game play. Clearly, they "strip" the hybrid environments of the digital:

Such as an authentic gambler, Jodi gambles the game revealing immediately the pack of lies on which the conventions - which make us perceive the game as an alternative believable reality in which experiencing some adventures - are based on and makes of the disbelief suspension an impossible passage. (Quaranta)

Once again, the story, the narrative and, eventually, the realistic appearance, represent the enemy: the cloak that hides our pristine experience of the real.

\section{The communicating vessels: Reversing the layers}

The continuous feedback between the cultural layer and the computer layer is implemented by transcoding our cultural achievements into the digital domain, and vice versa. Switching the context is another historical strategy to reset the audience's preconceptions. These context switches, in the medium of video games, can be developed by importing the algorithmic logic of the video games used for the motion of the bots and/or avatars, into our physical reality.

Death Animations (2006-07), by Brody Condon, is a live performance in which the performers slowly emulate the programmed gestures of death in the games. The physical evidence of the performance offers a new and disturbing vision of what looks familiar inside the video game. With the sound backing of binaural beats, the performers are induced to reach out-of-body experiences. This performance is inspired by Bruce Nauman's Tony Sinking in the Floor, Face Up and Face Down (1973): the actor was asked to imagine as if he were sinking into the floor. Condon is experimenting with cultural achievements and strategies developed in the 1960s. Now, they are used to address the context of the digital and its algorithmic logics. Still, the outcomes are similar: they remind us of our presence in the world and inform us about the physical nature we live in, in poetic ways.

Again, to grasp an experience of the real, preconceptions, assumed realities and representations have to be removed:

"To be a performance artist, you have to hate theatre," she replied. "Theatre is fake... The knife is not real, the blood is not real, and the emotions are not real. Performance is just the opposite: the knife is real, the blood is real, and the emotions are real." (Marina Abramovic, 2010).

\section{Conclusion}

The tangibility or intangibility of natural environments, as mediums for interventions by former and present artists, is just a technological circumstance: physical or not, there is a context in which we spend much our lives. What is at stake is the interest of questioning our visions of the world by rediscovering and experiencing what is immediately present: the way we see ourselves, in relation to land, trees, objects and others. Land Art, Povera and Performance Art are focused on such experiences. Likewise, a movement of artists working with video games shares the same concerns and strategies. They too perform inside environments, they also make a claim for a "natural" experience: walk, touch, transform and interact. Avatars offer us a virtual embodiment in a virtual space that is as real as the digital technologies that are influencing our minds and behaviors. Such experiences not only represent aesthetic updates of historical art movements and strategies; they also reflect the 
social concerns regarding today's reign of the digital, a relatively new cultural artifact subject to human interests. Our former cultural achievements are thus of help to us in our life today.

\section{References}

Bertol Brecht, 2016, Alienation Effect, Encyclopædia Britannica, The Editors of Encyclopædia Britannica, accessed 03/07/2016:

https://www.britannica.com/art/alienation-effect

Bittanti, Mateo, 2010, Interview: Miltos Manetas, The First Machinima-Maker, Game Art, accessed 7/31/2010:

http://www.gamescenes.org/2010/07/interview-miltos-manetas-the-first-machinimamaker.html

Galassi, Peter, 1981, Before Photography: Painting and the Invention of Photography (Long Island City, New York : Book Bindery,)

Games EduUu,

18/04/2015:

https://www.youtube.com/watch?v=y2gJGWFZTE0\&index=13\&list=PL9CE41F29A6763B95

Hunger, Francis, 1999, Perspective Engines: An interview with Jodi. In Video Games and Art (Bristol, UK, Intellect Books, 2007)

Jannson, Mattias, 2015, Art Around the World, From Japan to Cuba (Akarp, Sweden: jag behöver inget förlag,)

Manning, Chelsey, 2017, Chelsea Manning: The Dystopia We Signed Up For, The New York Times, accessed 13/09/2107 :

https://www.nytimes.com/2017/09/13/opinion/chelsea-manning-big-data-dystopia.html

Manovich, Lev, 2001, The Language of New Media, (Massachussets, MIT)

McLuhan, Marshall, 1964, Understanding Media: the Extensions of Man (NY, McGraw Hill)

Mirapaul, Matthew, 2003, Arts Online; Take That, Monica! Kapow, Chandler!, The New York Times, accessed 3/03/0213:

http://www.nytimes.com/2003/03/03/arts/arts-online-take-that-monica-kapow-chandler.html

Ortega y Gasset, José, 1925, The Dehumanization of Art: And Other Essays on Art, Culture, and Literature (Princeton University Press, 1948)

Taylor, Laurie N., 2002, Video Games: Perspective, Point-of-View, and Immersion (University of Florida)

Sean O’Hagan, 2010, Interview: Marina Abramovic, The Observer, accessed 3/10/2019:

https://www.theguardian.com/artanddesign/2010/oct/03/interview-marina-abramovic-performance-artist

Wertheim, M., 2000, The Pearly Gates of Cyberspace. A History of Space from Dante to the Internet. (New York, EEUU: W. W. Norton \& Company Inc.) 